\title{
Colectomy for idiopathic megarectum and megacolon
}

\author{
G Stabile, M A Kamm, P R Hawley, J E Lennard-Jones
}

\begin{abstract}
The outcome in 40 patients who underwent colectomy for idiopathic megacolon and megarectum over an 18 year period was evaluated. All patients had a radiologically dilated bowel and a bowel frequency of less than two per week. Twenty two patients had a caecorectal anastomosis, 11 had an ileorectal anastomosis (including one with a previous caecorectal anastomosis and four with a previous sigmoid resection), and seven had a sigmoid resection. The mean (range) age at operation was 35 (1769) years. All three operations resulted in a normal bowel frequency in more than $80 \%$ of patients but no patient with an ileorectal anastomosis experienced recurrent constipation. Thirty four patients experienced pain preoperatively and this was still present in 14 patients postoperatively. One patient died and four required subsequent laparotomy for bowel obstruction. The functional outcome in patients with dilatation of the whole colon and in those with dilatation of the left colon did not differ. Subsequent surgery for constipation was performed in three patients. Colectomy offers good results with few complications in the treatment of idiopathic megacolon, and an ileorectal anastomosis is the preferred operation.
\end{abstract}

Patients with severe constipation that is unresponsive to medical treatment tend to fall into two main groups. The first group comprises women of reproductive age who have a colon of normal diameter.' The colon looks normal macroscopically, but there is a disturbance of motility characterised by a decrease in the frequency and duration of propulsive mass movements. ${ }^{2}$ The standard surgical procedure in these patients is a subtotal colectomy with ileorectal anastomosis, and the results of this operation in this group of patients have been extensively reviewed..$^{3-5}$

The other main group consists of patients with an idiopathic megarectum, with or without megacolon. It is not known whether this condition is caused by an abnormality of the colonic

TABLE I Patients'details (values, mean (range))

St Mark's Hospital London

G Stabile

M A Kamm

P R Hawley

J E Lennard-Jones

Correspondence to:

Dr M A Kamm, St Mark's

Hospital, City Road, London

ECIV 2PS.

Accepted for publication

25 March 1991

\begin{tabular}{lcll}
\hline Age at operation (years) & $31(17-61)$ & $43(20-57)$ & $45(26-69)$ \\
Age onset (years) & $17(0-59)$ & $22(0-49)$ & $40(9-59)$ \\
Follow up (years) & $8(1-10)$ & $7(1-17)$ & $7(1-18)$ \\
$\begin{array}{l}\text { Childhood/adult onset } \\
\text { Male/female }\end{array}$ & $10 / 12$ & $4 / 7$ & $1 / 6$ \\
$\begin{array}{l}\text { Dilatation of colon and } \\
\text { rectum }\end{array}$ & $8 / 14$ & $4 / 7$ & $5 / 2$ \\
$\begin{array}{l}\text { Dilatation of rectosigmoid } \\
\text { only }\end{array}$ & 15 & 9 & 5 \\
\hline
\end{tabular}

muscle, its innervation, or the sphincter mechanism. It is important to exclude Hirschsprung's disease and also patients with chronic idiopathic intestinal pseudo-obstruction caused by myopathy who may also have upper gut involvement. In patients with idiopathic megarectum and megacolon, the symptoms are those of infrequent defecation, abdominal pain, abdominal distension, faecal impaction, and soiling. The onset of symptoms occurs in childhood or in adulthood. ${ }^{6}$ The results of colectomy in those with a dilated large bowel has been assessed in relatively few studies. ${ }^{7-9}$

We have reviewed the results of colectomy for idiopathic megarectum with or without megacolon in one hospital over an 18 year period (1970-89).

\section{Methods}

A survey of the hospital records indicated that 40 patients underwent a colectomy between July 1970 and January 1989. All patients have been included in the study. Twenty two of the 40 patients had a colectomy with a caecorectal anastomosis, 11 had a colectomy with an ileorectal anastomosis, and seven had a sigmoid colectomy. Postoperative information was available on 36 patients. In addition to review of the hospital notes, 24 patients were interviewed by one of the authors (GS).

Patients details are given in Table I. All patients had a rectal diameter greater than normal, that is greater than $6.5 \mathrm{~cm}$ in the lateral view of the pelvic brim on $x$ ray. ${ }^{10}$ The rectum was moderately dilated in most: the diameter in the lateral view ranged from 7 to $10 \mathrm{~cm}$ (mean 8.4 $\mathrm{cm}$ ). Eleven patients had dilatation of the rectosigmoid only, while 29 had dilatation of the whole colon and rectosigmoid (Table I). Colonic dilatation was assessed subjectively by the radiologist, based on apparent proximal enlargement together with loss of haustral pattern. The diameter of the colon was usually greater than $6 \mathrm{~cm}$ in the descending and $8 \mathrm{~cm}$ in the ascending colon. ${ }^{10}$ Transit studies were performed in 17 patients and these were prolonged in 15. Proctography was not routinely performed in these patients. Preoperative $x$ ray findings were compared with the diameter of the operative specimens. Hirschsprung's disease was excluded by a full thickness rectal biopsy specimen or by the presence of the rectosphincteric reflex, or both. All patients had a bowel frequency of two or less per week." Soiling was more common in those with childhood onset of symptoms (12 of 14 with soiling).

Twelve patients had had previous bowel surgery: appendicectomy (4), sigmoid resection (4), sigmoid colostomy (2), colectomy and caeco- 
rectal anastomosis (1), and left hemicolectomy (1). Seven patients had had previous manual evacuations.

Seven patients suffered from depression, two had mild intellectual impairment, one had considerable intellectual impairment, and one was epileptic. Other medical disorders included: one patient with diabetes and acromegaly, one patient with treated hypothyroidism and pancreatitis, and one patient with scoliosis.

\section{Results}

All resected specimens were of enlarged diameter. Five patients had melanosis coli, one patient had bowel hypertrophy, and one patient had stercoral ulceration; otherwise the specimens were macroscopically unremarkable. The nerve plexuses looked normal in all specimens on haematoxylin and eosin staining. There was complete agreement between the width of the colon on preoperative $x$ ray findings and the operative specimens in diameter size. The symptomatic results are presented in Tables II and III.

\section{COMPLICATIONS}

There was one death caused by abdominal sepsis in an elderly patient with diabetes and acromegaly. The only other early complications were two wound abscesses. Late complications were four bowel obstructions requiring laparotomy and one incisional hernia requiring repair.

\section{FURTHER SURGERY}

Failure to improve bowel frequency resulted in two patients having an excision of the caecum and an ileorectal anastomosis with development of normal bowel frequency. One patient underwent a division of puborectalis but there was still no improvement in bowel frequency.

\section{PREDICTIVE FACTORS}

Twenty nine patients had dilatation of the whole colon and 11 had dilatation of the left colon - the functional results were not different between the two groups (Table III).

TABle II Preoperative (Pre) and postoperative (Post) symptoms (values no (\%))

\begin{tabular}{|c|c|c|c|c|c|c|}
\hline & \multicolumn{2}{|c|}{ Caecorectal } & \multicolumn{2}{|l|}{ Ileorectal } & \multicolumn{2}{|l|}{ Sigmoid } \\
\hline & $\begin{array}{l}\text { Pre } \\
(n=22)\end{array}$ & $\begin{array}{l}\text { Post } \\
(n=20)\end{array}$ & $\begin{array}{l}\text { Pre } \\
(n=11)\end{array}$ & $\begin{array}{l}\text { Post } \\
(n=10)\end{array}$ & $\begin{array}{l}\text { Pre } \\
(n=7)\end{array}$ & $\begin{array}{l}\text { Post } \\
(n=6)\end{array}$ \\
\hline \multicolumn{7}{|l|}{ Bowel frequency: } \\
\hline$<2 /$ week & $22(100)$ & $3(15)$ & $11(100)$ & 0 & $7(100)$ & $1(16)$ \\
\hline 3/day-3/week & & $16(80)$ & & $9(90)$ & & $5(84)$ \\
\hline$>3 /$ day & 0 & $1(5)$ & 0 & $1(10)$ & 0 & \\
\hline Laxative use & $18(80)$ & $4(20)$ & $10(90)$ & $1(10)$ & $4(57)$ & $1(16)$ \\
\hline $\begin{array}{l}\text { Straining } \\
\text { Sting }\end{array}$ & $11(50)$ & $3(15)$ & $8(72)$ & $3(30)$ & $1(14)$ & 0 \\
\hline Faecal impaction & $9(40)$ & $2(10)$ & $4(36)$ & 0 & $1(14)$ & $1(16)$ \\
\hline Painful evacuation & $6(27)$ & $1(5)$ & $8(72)$ & $3(30)$ & $1(14)$ & 0 \\
\hline Digital evacuation & $4(18)$ & & $4(36)$ & & & 0 \\
\hline Abdominal pain & $19(86)$ & $9(45)$ & $9(81)$ & $4(40)$ & $6(85)$ & $1(16)$ \\
\hline Abdominal mass & $6(27)$ & $1(5)$ & $5(46)$ & 0 & $3(44)$ & $1(16)$ \\
\hline Abdominal distention & $22(100)$ & $7(35)$ & $11(100)$ & $4(40)$ & $7(100)$ & $2(34)$ \\
\hline Faecal incontinence & $7(32)$ & $1(5)$ & $6(54)$ & $5(50)$ & $1(14)$ & 0 \\
\hline \multicolumn{7}{|l|}{ Subjective wellbeing: } \\
\hline $\begin{array}{l}\text { Very well } \\
\text { Well }\end{array}$ & & $6(30)$ & & $4(40)$ & & $2(34)$ \\
\hline $\begin{array}{l}\text { Well } \\
\text { Poor }\end{array}$ & $\begin{array}{l}1(4) \\
16(73)\end{array}$ & $11(55)$ & $\begin{array}{l}3(27) \\
3(27)\end{array}$ & $\begin{array}{l}4(40) \\
2(20)\end{array}$ & $\begin{array}{l}2(28) \\
3(44)\end{array}$ & $\begin{array}{l}3(50) \\
1(16)\end{array}$ \\
\hline Very poor & $5(23)$ & $\begin{array}{l}2(10) \\
1(5)\end{array}$ & $\begin{array}{l}3(21) \\
5(46)\end{array}$ & $\begin{array}{l}2(20) \\
0\end{array}$ & $\begin{array}{l}3(44) \\
2(28)\end{array}$ & $\begin{array}{l}1(10) \\
0\end{array}$ \\
\hline
\end{tabular}

TABLE III Preoperative and postoperative symptoms (values no $(\%))$

\begin{tabular}{|c|c|c|c|c|}
\hline \multirow[b]{2}{*}{ Dilatation: } & \multicolumn{2}{|c|}{ Whole colon $(n=29)$} & \multicolumn{2}{|c|}{ Left colon $(n=11)$} \\
\hline & $\begin{array}{l}\text { Pre } \\
(n=29)\end{array}$ & $\begin{array}{l}\text { Post } \\
(n=26)\end{array}$ & $\begin{array}{l}\text { Pre } \\
(n=11)\end{array}$ & $\begin{array}{l}\text { Post } \\
(n=10)\end{array}$ \\
\hline \multicolumn{5}{|l|}{ Bowel frequency: } \\
\hline$<2 /$ week & $29(100)$ & $3(12)$ & $11(100)$ & $1(10)$ \\
\hline 3/day-3/week & & $22(84)$ & & $8(80)$ \\
\hline$>3 /$ day & & $1(4)$ & 0 & $1(10)$ \\
\hline Laxative use & $22(75)$ & $4(15)$ & $10(90)$ & $2(20)$ \\
\hline Straining & $17(58)$ & $4(15)$ & $6(55)$ & $2(20)$ \\
\hline Faecal impaction & $11(37)$ & $2(8)$ & $3(27)$ & $1(10)$ \\
\hline Painful evacuation & $12(41)$ & $3(12)$ & $4(36)$ & $1(10)$ \\
\hline Digital evacuation & $7(24)$ & & $1(9)$ & \\
\hline Abdominal pain & $25(92)$ & $10(40)$ & $9(81)$ & $4(40)$ \\
\hline Abdominal mass & $10(31)$ & $1(4)$ & $4(36)$ & $1(10)$ \\
\hline Abdominal distention & $29(100)$ & $9(36)$ & $11(100)$ & $4(40)$ \\
\hline Faecal incontinence & $9(31)$ & $4(15)$ & $5(45)$ & $2(20)$ \\
\hline \multicolumn{5}{|l|}{ Subjective wellbeing: } \\
\hline Very well & & $10(38)$ & & $2(20)$ \\
\hline Well & $3(10)$ & $12(46)$ & $3(27)$ & $6(60)$ \\
\hline Poor & $16(55)$ & $3(12)$ & $6(55)$ & $2(20)$ \\
\hline Very poor & $10(35)$ & $1(4)$ & $2(18)$ & \\
\hline
\end{tabular}

Recurrent constipation did not occur in any patient who had an ileorectal anastomosis. This is in contrast to three of 22 patients who had a caecorectal anastomosis, in whom constipation persisted postoperatively. Constipation also persisted in one of seven patients who had a sigmoid colectomy.

\section{Discussion}

Our results indicate that most patients undergoing a colectomy for idiopathic megarectum or megacolon develop a normal bowel frequency. This was further reflected in the fact that most of these patients stopped laxative use. The prevalence of straining and faecal impaction were also considerably improved. Most patients felt improved by surgery. In common with the results of colectomy for severe idiopathic constipation and a normal diameter colon, ${ }^{4}$ a considerable number of patients continued to experience some abdominal pain, although it was often improved. Persistent constipation occurred in $11 \%$ of patients with normal diameter colon, ${ }^{+}$ and in $11 \%$ of patients in this series - in the latter group, however, this may be related to retention of the caecum or a limited sigmoid resection.

One patient with a successful ileorectal anastomosis in this series had persistent constipation after a previous colectomy with caecorectal anastomosis. Furthermore, four patients in this series had had a previous sigmoid resection with persistent or recurrent constipation. None of the 11 patients who had an ileorectal anastomosis experienced recurrent constipation.

These findings suggest that an ileorectal anastomosis is the operation of choice in terms of avoiding recurrent constipation.

There are very few published studies on the results of colectomy for this condition, because few centres have a large experience. Lane and Todd ${ }^{7}$ reported a series of 42 patients from our hospital, 14 of whom had surgical intervention. Of these, five patients with a caecorectal and four with an ileorectal or ileosigmoid anastomosis achieved relatively satisfactory results. Three patients with a sigmoid colectomy had mixed results, as did two patients with a left hemicolectomy. McReady and $B^{2}{ }^{8}{ }^{8}$ reported the results of surgery in 23 patients. Eleven patients 
who had a colectomy fared well, while six of eight patients who had an anterior resection also fared well. Four patients who had an endorectal pull through did not do well, largely because of pelvic sepsis. Belliveau et $a l^{9}$ reported a series of 48 patients. Patients who underwent either subtotal colectomy or sigmoid resection fared well on the whole.

A variety of other operations have been tried in this condition, including the Duhamel procedure, ${ }^{1213}$ anorectal myectomy,,$^{14}$ and more recently a coloanal anastomosis ${ }^{1516}$ or restorative ileoanal pouch anastomosis. ${ }^{17}$ In those with a grossly dilated rectum, it may not be possible to undertake resection with rectal anastomosis, and in these patients the Duhamel procedure is an alternative. ${ }^{1318}$ The results of this procedure are mixed, and not as uniformly satisfactory when compared with its use for Hirschsprung's disease. ${ }^{19}$ Anorectal myectomy may have a place but there is limited data about its value. A distal colonic and rectal resection with coloanal anastomosis have given good results in a few selected patients, but the operation is more complex than a straightforward resection. ${ }^{16}$ In one series, five patients had a restorative proctocolectomy for a grossly dilated rectum and colon, two had an anastomotic leak and one of these developed recurrent small bowel obstruction, but none developed recurrent constipation. ${ }^{17}$ Ileal pouch operations may be useful in the rare patient in whom the only alternative is an end ileostomy.

By comparison with these other operations, colectomy seems to give good functional results with a low morbidity. For those in whom the rectum is not enormously dilated, we feel it is the operation of choice in this condition. An ileorectal anastomosis seems to give the most satisfactory results in this condition. Although the proportion who were incontinent postoperatively was greater in the ileorectal group, this difference may be partly due to persistent consti- pation in some patients who had a caecorectal anastomosis.

GS is supported by The British Council. MAK is supported by the St Mark's Research Foundation.

1 Preston DM, Lennard-Jones JE. Severe chronic constipation of young women: idiopathic slow transit constipation. Gut $1986 ; 27: 41-8$

2 Bassotti G, Gaburri M, Imbimbo BP, et al. Colonic mass movements in idiopathic chronic constipation. Gut 1988; 29: movement

3 Yoshioka K, Keighley MRB. Clinical results of colectomy for severe constipation. Brf Surg 1989; 76: 600-4.

$4 \mathrm{Kamm}$ MA, Hawley PR, Lennard-Jones JE. Outcome of colectomy for severe idiopathic constipation. Gut 1988; 29 969-73

5 Preston DM, Hawley PR, Lennard-Jones JE, Todd IP Results of colectomy for severe idiopathic constipation in women (Arbuthnot Lane's disease). Brf Surg 1984; 71: 547 52.

6 Barnes PRH, Lennard-Jones JE, Hawley PR, Todd IP. Hirschsprung's disease and idiopathic megacolon in adults and adolescents. Gut 1986; 27 : 534-41.

7 Lane RHS, Todd IP. Idiopathic megacolon; a review of 42 cases. BrF Surg 1977; 64: 305-10.

8 McReady RA, Beart RW. The surgical treatment of incapacitating constipation associated with idiopathic megacolon. Mayo Clin Proc 1979; 54: 779-83.

9 Belliveau P, Goldberg SM, Rothenberger DA, Nivatvongs S Idiopathic acquired megacolon: the value of subtotal colectomy. Dis Colon Rectum 1982; 25: 118-21.

10 Preston DM, Lennard-Jones JE, Thomas BM. Towards a radiological definition of idiopathic megacolon. Gastrointes Radiol 1985; 10: 167-9.

11 Drossman DA, Sandler RS, McKee DC, Lovitz AJ. Bowe patterns among subjects not seeking health care. Gastroenterology 1982;83: 529-34.

12 Parc R, Berrod JL, Tussiot J, Loygue J. Le megacolon de l'adulte. A propos de 76 cas. Ann Gastroenterol Hepatol 1984; 20: $133-41$.

13 Stabile G, Kamm MA, Hawley PR, Lennard-Jones JE. Results of the Duhamel operation in the treatment of idiopathic megarectum and megacolon. Br F Surg 1991; 78: 661-3.

14 Hata Y, Sasaki F, Uchino J. Sphincteromyectomy and sphincteroplasty in chronic constipation with megarectum. f Pediatr Surg 1988; 23: 141-2

15 Vernava AM, Robbins PL, Brabbee GW. Restorative resection: coloanal anastomosis for benign and malignan disease. Dis Colon Rectum 1989; 32: 690-3.

16 Stabile G, Kamm MA, Hawley PR, Phillips RKS, LennardJones JE. Alternative surgery for idiopathic megarectum and megacolon. Gut 1991; 32: A575.

17 Hosie KB, Kmiot WA, Keighley MRB. Constipation: another indication for restorative proctocolectomy. Br $\mathcal{F}$ Surg 1990; indication $801-2$.

18 Stabile G, Kamm MA, Lennard-Jones JE, Hawley PR. Idiopathic megarectum and megacolon: which operation offers the best results? Gut 1990; 31: A1172.

19 Elliot MS, Todd IP. Adult Hirschsprung's disease: results of the Duhamel procedure. Br F Surg 1985; 72: 884-5. 